\title{
Association between Dietary and Lifestyle Indices and Colorectal Cancer in Oman: A Case-Control Study
}

\author{
Rose N Mafiana ${ }^{1}$, Ahmed S Al Lawati ${ }^{2}$, Mostafa I Waly ${ }^{3}$, Yahya Al Farsi ${ }^{4}$, \\ Maimouna Al Kindi ${ }^{1}$, Mansour Al Moundhri ${ }^{2 *}$
}

\begin{abstract}
Background: Colorectal cancer (CRC) represents a heterogeneous group of diseases characterized by uncontrolled growth and spread of abnormal cells in the body. CRC vary on the basis of both the biologic features of the disease and its associated lifestyle characteristics. The risk of CRC increases with several modifiable factors including obesity, physical inactivity, a diet high in red or processed meat, heavy alcohol consumption, and possibly inadequate intake of fruits and vegetables. We aimed to establish a baseline data for dietary and lifestyle characteristics of Omani adults diagnosed with CRC. Methods: A Case control study conducted at Sultan Qaboos University Hospital, a referral hospital for CRC patients in Oman, and included 279 subjects (109 diagnosed CRC cases and 170 matched controls). All study subjects were recruited on volunteer basis and personally interviewed for preset questions related to sociodemographic data, anthropometric assessment, dietary intake and physical activity. Results: There was no significant difference between cases and controls regarding smoking, alcohol intake, physical activity and dietary fiber intake. However the enrolled cases were more overweight $(\mathrm{OR}=3.27 .95 \% \mathrm{CI}: 1.91,7.27)$, and, had a higher caloric $(\mathrm{p}=0.001)$ and macronutrient intake (carbohydrate: $\mathrm{p}=0.001$; protein: $\mathrm{p}=0.017$; saturated fat: $\mathrm{P}=0.034$ ) than the controls. In addition, the dietary pattern of the cases was characterized by a trend towards low vegetables and fruits intake. Conclusion: CRC maybe prevented through dietary management of high risk groups. This primary prevention approach will ultimately reduce the burden of CRC in Oman.
\end{abstract}

Keywords: Colorectal cancer- diet- lifestyle- Oman

Asian Pac J Cancer Prev, 19 (11), 3117-3122

\section{Introduction}

Colorectal cancer (CRC) is the third most common cancer in the world and the fourth in cancer-related deaths after lung and breast cancers respectively (Fitzmaurice et al., 2015). It is predicted that about 2.4 million cases will be diagnosed annually worldwide by 2035 (Torre et al., 2015). In 2013, CRC accounted for 1.6 million of the 14.9 million global incident cancer cases. Within the same period, CRC was responsible for more than 700,000 of the total 8.2 million cancer- related deaths (Fitzmaurice et al., 2015). According to literature, incidence rates for CRC are generally higher in more developed countries of the West (Fitzmaurice et al., 2015). However, the Middle Eastern countries such as Oman, previously considered as low-risk regions for $\mathrm{CRC}$, are witnessing a rising trend (Hakulinen, 2007; Fitzmaurice et al., 2015). The 2006 Oman cancer registry report on the ten most common cancers in Oman indicated that CRC was the 7th most common in Omani men and 10th among women respectively in that year (Oman National Cancer Registry, 2006). However, by 2012, CRC had become the most frequent cancer among Omani men and the third most common in Omani women with incidence rates of 10.2 and 8.5 per 100,000 cases for men and women respectively (Oman National Cancer Registry, 2012). Within the same period, CRC accounted for $9.0 \%$ of all-cause mortality in adult Omani males and $8.3 \%$ in females (Oman National Cancer Registry, 2012; World Health Organization, 2014).

$\mathrm{CRC}$ is an important public health problem. About one in three people diagnosed with CRC die of the disease within 5 years after diagnosis (American Cancer Society, 2016). In addition to the human cost, the tangible and intangible costs of treating CRC are enormous. The direct medical costs for CRC treatment in the U.S. in 2011 was $\$ 88.7$ billion (American Cancer Society, 2016). These figures do not include the indirect costs such as patient- time involved with receiving medical care and productivity losses among patients and caregivers (Yabroff et al., 2013;

${ }^{1}$ Department of Pharmacy, ${ }^{2}$ Department of Internal Medicine, ${ }^{4}$ Department of Family Medicine and Public Health, College of Medicine and Health Sciences, ${ }^{3}$ Department of Food Science and Nutrition College of Agricultural and Marine Sciences, Sultan Qaboos University Hospital, Oman.*For Correspondence: mansours@squ.edu.om 
American Cancer Society, 2016). Although there has been a marked reduction in $\mathrm{CRC}$ incidence and death rates across developed countries due to improved screening services and specialized care (American Cancer Society, 2016), screening and early detection services for CRC are lacking in Oman. As a result of this, many CRC cases are detected in the late stages where the only option of treatment is palliative. Furthermore, apart from a small number of CRC cases related to genetic disposition and advanced age, up to $90 \%$ of CRC cases are non-hereditary, and have been linked to modifiable behavioral practices related to diet, physical inactivity, obesity, heavy alcohol consumption and tobacco use (MacFarlane et al., 2007; Kirkegaard et al., 2010; Spring et al., 2012; Jones-McLean et al., 2015).

Many studies on Western populations have looked into the association between diet and lifestyle factors and CRC (Levi et al., 2002; Boyle et al., 2013; Johnson et al., 2013; Baroudi et al., 2014). Of the few such studies conducted in the Arab countries of the Middle East (Arafa et al., 2011; Alamri et al., 2014; Azzeh et al., 2017), none has examined the association between dietary and lifestyle indices and $\mathrm{CRC}$ in the Omani population despite the documented rise in CRC incidence in Oman over the past decade. Therefore, the overall aim of this study was to examine the association between dietary and lifestyle indices, and CRC among Omani cases and controls attending a tertiary hospital in Oman. The specific objectives were: 1- To compare the lifestyle characteristics of cases and controls, 2- Determine if there was any difference in daily macronutrient intake between cases and controls, 3-Explore the sociodemographic and lifestyle indices that predicted $\mathrm{CRC}$ while controlling for potential confounding variables.

\section{Materials and Methods}

\section{Study Population}

This case- control study was conducted from February to November 2016, among participants attending Sultan Qaboos University Hospital (SQUH), a tertiary hospital in Muscat, Oman. The study was approved by the Medical Research and Ethics Committee of SQUH (MREC \#1232).

\section{Sample size \&power calculation}

Allowing an error rate of $2.5 \%$, a level of significance (type 1 error) of 5\% and 95\% confidence interval and with a priori estimate of $10 \%$ prevalence of CRC in controls and a least odds ratio of 2.5, the OpenEpi sample size calculator indicated that a sample size of 228 (114 participants in each group) was required to achieve a power of $80 \%$ in this study.

\section{Study Participants}

The study participants included 279 adults aged 18 years and above (109 cases and 179 controls) of similar ethnicity, culture, and quality of care. The cases were selected by convenience sampling and the controls by simple random sampling.

\section{Selection of Cases}

Cases were selected from among Omani patients aged 18 years or above with histologically proven CRC (ICD-10: 18.0, 18.2 to $18.9,19$ and 20) who attended the outpatient oncology clinic or, were admitted into the oncology wards within the period of the study. One hundred and twenty cases were approached out of which 109 cases consented to participate in the study yielding a response rate of $91 \%$.

\section{Selection of Controls}

The controls were randomly selected from among patients admitted in the ENT, ophthalmology and surgical wards with a wide range of acute non-malignant conditions that ranged from cataract, slipped discs, low back pain, simple fractures, sprains, minor traumas, hernia repair, gall bladder stones and osteoarthritis Two hundred and forty controls were approached out of which 170 consented to participate in the study to yield a response rate of $75 \%$.

Potential participants were approached by trained research assistants who explained the purpose of the study and the details of the methodology to them. All potential participants received an information sheet that covered all aspects of the study. Participants who agreed to participate in the study were asked to sign an informed consent form, and were provided with contacts of the investigators for any further inquiries. Therefore, a total of 279 participants were included in the analysis.

\section{Study tools and data collection}

A structured questionnaire that has been tested for validity, reproducibility and reliability (Arafa et al, 2011) was used to collect the data during personal interviews. The questionnaire included sections on dietary characteristics, socio-demographic variables, relevant co-morbidities, lifestyle characteristics, and anthropometric measurements. Participants were asked to report the frequency and portion sizes for each of 33 food items in 8 food groups commonly eaten in Oman, prior to CRC diagnosis for cases, or, prior to their admission, for controls. Participants were also asked whether or not they used tobacco, consumed alcohol, and took part in selected physical activity aimed at achieving at least 150 minutes of moderate-intensity or 75 minutes of vigorous-intensity throughout the week, according to the World Health Organization recommendation for adults (Hamer et al., 2013; WHO, 2016). Demographic variables included gender, age, education and marital status. All interviews were conducted in the hospital during admission or outpatient consultation.

\section{Statistical Analysis}

Prior to conducting the statistical analysis, physical activity, was recoded and dichotomized as active/not active. The "not active" category comprised participants who reported less than the WHO recommended standard physical activity whereas the "active" category was made up of participants who engaged in moderate or vigorous physical activity according to the standard recommendation of the World Health Organization, (WHO, 2016). Body mass index (BMI) was categorized 
into three levels according to the WHO criteria as $18.5-24.99 \mathrm{~kg} / \mathrm{m}^{2}, 25-29.99 \mathrm{~kg} / \mathrm{m}^{2}, \geq 30 \mathrm{~kg} / \mathrm{m}^{2}$ representing normal weight, overweight and obese respectively (WHO, 2015).

To evaluate the statistical significance of differences among proportions of categorical data, Chi-square analyses were used. The non-parametric Fisher's exact test (two-tailed) replaced the Chi-square test in cases of small sample size, where the expected frequency was less than 5 in any of the cells in the $2 \times 2$ tables. Dietary data was analyzed based

Table 1. Socio-Demographic and Lifestyle Characteristics of Study Participants, Oman, 2016.

\begin{tabular}{|c|c|c|c|}
\hline Variable & $\begin{array}{c}\text { Cases } \\
(\mathrm{N}=109) \\
\mathrm{N}(\%)\end{array}$ & $\begin{array}{c}\text { Controls } \\
\begin{array}{c}(\mathrm{N}=170) \\
\mathrm{N}(\%)\end{array}\end{array}$ & P-value \\
\hline \multicolumn{4}{|l|}{ Age (years) } \\
\hline$\leq 40$ & $15(13.8)$ & $36(21.2)$ & 0.07 \\
\hline $41-60$ & $44(40.4)$ & $78(45.9)$ & \\
\hline$>61$ & $50(45.9)$ & $56(32.9)$ & \\
\hline \multicolumn{4}{|l|}{ Gender } \\
\hline Male & $65(59.6)$ & $76(53.9)$ & \\
\hline Female & $44(40.4)$ & $94(55.3)$ & 0.02 \\
\hline \multicolumn{4}{|l|}{ Occupation } \\
\hline Unemployed & $40(36.7)$ & $52(30.7)$ & \\
\hline Unskilled Worker & $31(25.7)$ & $66(38.8)$ & \\
\hline Self employed & $28(25.7)$ & $66(38.8)$ & 0.005 \\
\hline Skilled worker & $10(9.2)$ & $25(14.7)$ & \\
\hline \multicolumn{4}{|l|}{ Education } \\
\hline No/some schooling & $52(47.7)$ & $54(31.8)$ & \\
\hline High School & $28(25.7)$ & $55(32.4)$ & 0.03 \\
\hline University/Technical & $29(26.6)$ & $54(35.9)$ & \\
\hline \multicolumn{4}{|l|}{ Marital Status } \\
\hline Single & $6(5.5)$ & $13(7.6)$ & \\
\hline Married & $84(77.1)$ & $127(74.7)$ & \\
\hline Divorced/Widow & $19(17.4)$ & $30(17.6)$ & 0.78 \\
\hline \multicolumn{4}{|l|}{ Family History } \\
\hline No & $97(89)$ & $161(94.7)$ & 0.08 \\
\hline Yes & $12(11.0)$ & $9(5.3)$ & \\
\hline \multicolumn{4}{|l|}{ Smoking } \\
\hline Never & $81(74.3)$ & $131(77.1)$ & \\
\hline Former/Current & $28(25.7)$ & $39(22.9)$ & 0.35 \\
\hline \multicolumn{4}{|l|}{ Alcohol Intake } \\
\hline Never & $98(89.9)$ & $149(87.6)$ & \\
\hline Former/Current & $11(10.1)$ & $21(12.4)$ & 0.35 \\
\hline \multicolumn{4}{|l|}{ Physical Activity } \\
\hline Sedentary & $58(53.2)$ & $96(56.5)$ & \\
\hline Active & $51(46.8)$ & $74(43.5)$ & 0.34 \\
\hline \multicolumn{4}{|l|}{ Body Mass Index } \\
\hline Normal weight & $39(38.2)$ & $39(23.2)$ & \\
\hline Overweight & $33(32.4)$ & $84(43.3)$ & \\
\hline Obese & $30(29.4)$ & $45(26.8)$ & $<.001$ \\
\hline
\end{tabular}

on the Food Guide Pyramid from US Department of Agriculture according to the number of daily servings and the frequency of consumption (Willett and Ludwig, 2011). Dietary data were expressed as mean \pm standard deviation. The student unpaired t-test and correlation coefficients were used for mean comparisons. The odds ratios (OR) and 95\% confidence intervals (CI) obtained from multivariable logistic regression models were taken as the measures of predictors of CRC. All statistical analyses were conducted using Statistical Package for Social Sciences (SPSS 21.0) and statistical significance was set at $\mathrm{p}$-value of $\leq 0.05$.

\section{Results}

A total 270 participants were included in this study of which 109 (39.9\%) were cases and 170 (60.1\%) were controls. The sociodemographic characteristics of CRC cases and controls are as shown in Table 1.The mean age for cases and controls was $53.69 \pm 14.22$, and $57.35 \pm 14.08$ respectively. There were more participants of younger age, $36(21.2 \%)$ in controls compared to cases 15 (13.8\%). Compared to cases, controls had significantly higher educational qualification and were more in the skilled and professional occupations $(\mathrm{P}<0.05)$. There were no statistically significant differences between cases and controls with regards to smoking, alcohol intake and physical activity. However, the control group was significantly more overweight (43.3\%) than the CRC cases $(32.4 \%, \mathrm{P}<0.0001)$.

The food consumption frequency among the study

Table 2. Food Consumption Frequency of Study Participants, Oman, 2016

\begin{tabular}{cccc}
\hline Food group (servings/ day) & $\begin{array}{c}\text { Cases } \\
(\mathrm{N}=109) \\
\mathrm{N}(\%)\end{array}$ & $\begin{array}{c}\text { Controls } \\
(\mathrm{N}=170)\end{array}$ & P-value \\
& $\mathrm{N}(\%)$ & \\
\hline Bread, Cereal, Rice and Pasta & & & $\mathrm{P}>0.05$ \\
$<6$ & $32(29.4)$ & $43(25.3)$ & \\
$6-11$ & $35(32.1)$ & $67(38.8)$ & \\
$\geq 11$ & $42(38.5)$ & $61(35.9)$ & \\
Vegetables & & & $\mathrm{P}<0.05^{*}$ \\
$<3$ & $57(52.2)$ & $16(9.4)$. & \\
$3-5$ & $27(24.6)$ & $56(32.9)$ & \\
$\geq 5$ & $25(23.2)$ & $98(57.7)$ & \\
Fruits & & & $\mathrm{P}<0.05^{*}$ \\
$<2$ & $41(37.6)$ & $55(32.4)$ & \\
$2-4$ & $47(43.1)$ & $76(44.7)$ & \\
$>4$ & $21(19.3)$ & $29(22.9)$ & \\
Milk, Yogurt and Cheese & & & $\mathrm{P}>0.05$ \\
$<2$ & $83(76.1)$ & $141(82.9)$ & \\
$2-3$ & $20(18.1)$ & $25(14.7)$ & \\
$\geq 3$ & $6(5.8)$ & $4(2.3$ & \\
Meat, Poultry, Fish & & & $\mathrm{P}>0.05$ \\
$<2$ & $11(10.1)$ & $22(13)$ & \\
$2-3$ & $13(11.8)$ & $32(18.8)$ & \\
$\geq 3$ & $85(78.1)$ & $116(68.2)$ & \\
\hline
\end{tabular}

*Significant difference 
Table 3. Logistic Regression Analysis of Potential Predictors of CRC among Study Groups Oman, 2016

\begin{tabular}{|c|c|c|c|c|}
\hline \multirow[b]{2}{*}{ Variable } & \multicolumn{2}{|l|}{ Crude } & \multicolumn{2}{|l|}{ *Adjusted } \\
\hline & OR $(95 \% \mathrm{CI})$ & P-value & OR $(95 \% \mathrm{CI})$ & P-value \\
\hline \multicolumn{5}{|l|}{ Age (years) } \\
\hline$\leq 40$ & 1 & & 1 & \\
\hline $41-60$ & $0.51(0.25,1.03$ & 0.06 & $0.86(0.40,1.88)$ & 0.71 \\
\hline$\geq 61$ & $0.65(0.38,1.22)$ & 0.12 & $0.42(0.29,1.55)$ & 0.35 \\
\hline \multicolumn{5}{|l|}{ Gender } \\
\hline Female & 1 & & 1 & \\
\hline Male & $3.30(1.52,7.19)$ & & $2.38(1.28,4.35)$ & 0.006 \\
\hline \multicolumn{5}{|c|}{ Family History of CRC } \\
\hline No & 1 & & 1 & \\
\hline Yes & $3.07(1.04,2.35)$ & 0.04 & $3.23(1.18,8.33)$ & 0.02 \\
\hline \multicolumn{5}{|c|}{ Body Mass Index } \\
\hline$\leq 24.99$ & 1 & & 1 & \\
\hline $25-29.99$ & $2.36(1.19,4.47)$ & 0.02 & $3.27(1.91,7.27)$ & 0.00 \\
\hline$\geq 30$ & $0.55(0.30,1.02$ & 0.06 & $1.58(0.78,3.18)$ & \\
\hline \multicolumn{5}{|c|}{ Alcohol Consumption } \\
\hline No & 1 & & 1 & \\
\hline Yes & $0.67(0.23,1.93$ & & $0.91(0.32,2.58)$ & 0.86 \\
\hline \multicolumn{5}{|l|}{ Smoking } \\
\hline No & 1 & & 1 & \\
\hline Yes & $1.13(0.63,2.06)$ & & $1.62(0.93,2.84)$ & 0.12 \\
\hline \multicolumn{5}{|c|}{ Physical Activity } \\
\hline Not Active & 1 & & 1 & \\
\hline Active & $1.36(0.80,2.33$ & 0.26 & $1.25(0.76,2.06)$ & 0.37 \\
\hline
\end{tabular}

*Adjusted for age

participants is as listed in Table 2. The enrolled cases consumed significantly lower amounts of vegetables and fruits $(p<0.05)$. There were no statistically significant differences in the consumption of breads, milk/milk products, and meat between the $\mathrm{CRC}$ cases and controls. The average daily consumption for proteins, total fat, and carbohydrates were significantly higher among CRC cases compared to controls $(\mathrm{p}<0.05)$.

Table 3 shows the crude and adjusted logistic analysis of selected confounding variables. The crude odds ratio indicated that gender, family history of $\mathrm{CRC}$ and BMI were associated with CRC $(\mathrm{p}<0.05)$. This effect remained and was increased after adjusting for age (gender: $\mathrm{OR}=2.38,95 \% \mathrm{CI}: 1.28,4.35$ ), (family history of $\mathrm{CRC}$ : $\mathrm{OR}=3.23,95 \% \mathrm{CI}: 1.18,8.33$ ), and (BMI: $\mathrm{OR}=3.27 .95 \% \mathrm{CI}: 1.91,7.27$ ).

\section{Discussion}

To our knowledge, this study is the first study to examine the association between diet and lifestyle indices, and CRC among the Omani population. In our study, the dietary pattern of CRC cases had a statistically significant trend towards low vegetables and fruits intake which is similar to the finding by other authors from Saudi Arabia (Alamri et al., 2014; Azzeh et al., 2017). These authors examined the dietary habits of CRC cases and matched controls among a sample of Saudi participants and found that participants in the control group consumed more fruits and vegetables than the CRC cases. Furthermore, our study showed that the total caloric intake was significantly higher in CRC cases than in controls. This is consistent with the finding of other authors who reported that CRC cases consumed higher daily and total calories than controls (Alamri et al., 2014). Major health organizations such as the WHO, World Cancer Research Fund (WCRF), and, the American Institute for Cancer Research (AICR), have emphasized the important role that diet plays in the risk of CRC. These organizations recommend that diets rich in whole grains, fruits, vegetables, monounsaturated fats, dietary fibers and nuts are essential to reduce the burden of CRC and should be consumed in preference to processed and energy-rich foods and sugar sweetened beverages (WHO, 2010; AICR, 2016; WCRF, 2017). In our study, CRC cases consumed fewer vegetables and fruits than controls. Total caloric intake was also more in cases than in controls. These findings from our study provide insight into the dietary habits of Omani CRC patients which can form the basis for public awareness/ education interventions to reduce the burden of CRC in the Omani population.

Our study revealed that gender, overweight and family history were independent risk factors for CRC. Epidemiological evidence suggests that men are at 
a slightly higher risk for cancers than females with a higher lifetime probability of being diagnosed with an invasive cancer compared to women (Siegel et al., 2012). In our study, males were two times more likely to develop CRC than women. Similar to our findings, other authors found a higher risk of CRC in men compared to women (Campbell et al., 2010). However, contrary to our findings, some other authors found that women were more likely to develop CRC than men (He et al., 2010). Given these inconsistencies, further studies are necessary to further elucidate the association between gender and the risk of $\mathrm{CRC}$ in the Omani population.

Our study revealed that having a family history of CRC was associated with almost 3 times higher risk of developing CRC in Omani adults. Similarly, findings from a metaanalysis showed that individuals with a family history of $\mathrm{CRC}$ in a first degree relative were almost two times more likely to develop CRC (Johnson et al., 2010). In another study, the authors found that among 12 non-screening risk factors of CRC, having a family history of CRC in a first degree relative was associated with a higher risk of CRC than other factors such as increased BMI and red meat consumption (Powell et al., 2013).

In our study, being overweight was associated with more than 3 times higher risk of CRC compared to having normal weight. Similarly, recent systematic review and meta-analyses of more than 1000 observational studies showed sufficient evidence that high Body Mass Index (BMI), a marker of overweight and obesity was significantly associated with the risk of CRC (WHO, 2015; Lauby-Secretan et al., 2016). The causal link between obesity and $\mathrm{CRC}$ has been attributed to metabolic and endocrine abnormalities involving sex hormone metabolism, insulin and insulin-like growth factor signaling, and, oxidative stress arising from release of inflammatory cytokines and reactive oxygen and nitrogen species (Wong et al., 2012; Ma et al., 2013). Studies have shown that obesity prevalence is on the rise in Oman. In 2010 , about $20 \%$ of the Omani population was obese (Al-Riyami, 2010). By 2014, the figures had risen to $25 \%$ (ALNohair, 2014). Current WHO estimates indicate that as much as $27.2 \%$ adult Omani males and $37.7 \%$ females are obese (WHO, 2015).

The results of this study did not reveal an evidence for significant association between smoking and CRC or between alcohol consumption and CRC which is consistent with the findings from other studies McCleary et al., 2010; Rueda et al., 2012; Nordenvall et al., 2014).

This case control study may have been hampered by some limitations. First, this was a hospital based case-control study where both cases and controls were selected from the same hospital. Therefore, hospital-patient selection bias may have resulted in an underestimated odds ratio. However, controls were chosen from among patients who were admitted to the hospital for reasons unrelated to CRC, therefore, the potential for hospital-patient selection bias in this study was minimized. Secondly this study was limited to patients who attended one of two centers that treat $\mathrm{CRC}$ in Oman; hence, the findings from this research may not be representative of the general population in Oman.
Dietary and Lifestyle Indices and Colorectal Cancer

Thirdly, information exposure misclassification and recall bias arising from the inability of participants to correctly recall their dietary habits during the intervieweradministered food frequency questionnaire may have hampered our result. Moreover, information bias would have also occurred if participants were not honest in their responses to questions on alcohol consumption given that Oman is a Muslim country where alcohol consumption is prohibited.. Finally, being an observational study design, other unknown confounders could have influenced our results plus, cause and effect could not be determined.

In conclusion, our study results have provided baseline diet and lifestyle indices that may influence CRC in Oman. The enrolled CRC cases consumed lower fruits and vegetables than healthy controls. Moreover, higher overall caloric intake was observed among enrolled cases compared to the controls. Our results also showed that male gender, having a family history of CRC and being overweight increased the risk of CRC. Given that overweight and obesity result from an imbalance between energy intake and expenditure, and are risk factors for many chronic diseases, primary prevention targeted towards reducing excess body weight has the potential to reduce the burden of CRC in Oman.

\section{Disclosure}

The authors report no conflicts of interest in this work.

\section{Acknowledgments}

The authors would like to acknowledge the Nursing directorate, clinical nurse specialists in oncology, nursing staff of outpatient clinics, head nurses of oncology wards, and the pharmacy staff at SQUH for their valuable support in conducting this study.

\section{References}

Alamri FA, Saeedi MY, Kassim KA (2014) Dietary and other risk factors for colo-rectal cancer in Saudi Arabia. J Med Med Sci, 5, 222-9.

ALNohair S. (2014). Obesity in gulf countries. Int $J$ Health Sci, 8, 79 .

Al-Riyami A (2010). Type 2 Diabetes in Oman: Can we learn from the Lancet editorial. Oman Med J, 25,153.

American Cancer Society (2016). Colorectal cancer overview." Retrieved from http://www.cancer.org/cancer/ colonandrectumcancer/detailedguide/colorectal-cancerwhat-is-colorectal-cancer.

American Institute for Cancer Research (2016). Obesity and cancer: What you need to know. Retrieved from http://www. aicr.org/enews/.

Arafa MA, Waly MI., Jriesat S, Al Khafajei A Sallam S (2011). Dietary and lifestyle characteristics of colorectal cancer in Jordan: a case-control study. Asian Pac J Cancer Prev, 12, 1931-6.

Azzeh FS, Al Shammari EM, Alazzeh AY, et al (2017). Healthy dietary patterns decrease the risk of colorectal cancer in Mecca Region, Saudi Arabia: a case control study. BMC Public Health, 17, 607.

Bardou M, Barkun AN, Martel M (2013). Obesity and colorectal cancer. Gut, 62, 933-47

Baroudi O, Chaaben AB, Mezlini A, et al (2014). Impact of 
lifestyle factors and nutrients intake on occurrence of gastrointestinal cancer in Tunisian population. Tumour Biol, 35, 5815-22.

Boyle T, Fritschi L, Platell C, Heyworth J (2013). Lifestyle factors associated with survival after colorectal cancer diagnosis. Br J Cancer, 109, 814-22.

Campbell PT, Deka A, Jacobs EJ, et al (2010). Prospective study reveals associations between colorectal cancer and type 2 diabetes mellitus or insulin use in men. Gastroenterology, 139, 1138-46.

Fitzmaurice C, Dicker D, Pain A, et al (2015). The global burden of cancer 2013. JAMA Oncol, 1, 505-27.

Hakulinen T (2007). Gastrointestinal tract cancers-global burden and trends. Acta Oncol, 46.3, 400-1.

Hamer M, Lavoie KL, Bacon SL (2014). Taking up physical activity in later life and healthy ageing: the English longitudinal study of ageing. Br J Sports Med, 48, 239-43.

He J, Stram DO, Kolonel LN, et al (2010). The association of diabetes with colorectal cancer risk: the Multiethnic Cohort. Br J Cancer, 103, 120-6.

Jarvandi S, Davidson NO, Schootman M (2013). Increased risk of colorectal cancer in type 2 diabetes is independent of diet quality. PLoS One, 8, e74616.

Johnson CM, Wei C, Ensor JE (2013). Meta-analyses of colorectal cancer risk factors. Cancer Causes Control, 24, 1207.

Jones-McLean E, Hu J, Greene-Finestone LS, de Groh MA (2015). A DASH dietary pattern and the risk of colorectal cancer in Canadian adults. Health Promot Chronic Dis Prev Can, 35, 12.

Neumann K, Mahmud SM, McKay A, et al (2015). Is obesity associated with advanced stage or grade of colon cancer?. Can J Surg, 58, 140.

Kirkegaard H, Johnsen NF, Christensen J, et al (2010). Association of adherence to lifestyle recommendations and risk of colorectal cancer: a prospective Danish cohort study. Br Med J, 341, c5504.

Lauby-Secretan B, Scoccianti C, Loomis D, et al (2016). Body fatness and cancer-viewpoint of the IARC Working Group. N Engl J Med, 375, 794-8.

Levi F, Pasche C, Lucchini F, La Vecchia C (2002). Diabetes mellitus, family history, and colorectal cancer. J Epidemiol Community Health, 56, 479-80.

Ma Y, Yang Y, Wang F, et al (2013). Obesity and risk of colorectal cancer: a systematic review of prospective studies. PLoS One, 8, e53916.

MacFarlane AJ, Stover PJ (2007). Convergence of genetic, nutritional and inflammatory factors in gastrointestinal cancers. Nutr Rev, 65, s3.

McCleary NJ, Niedzwiecki D, Hollis D, et al (2010). Impact of smoking on patients with stage III colon cancer. Cancer, 116, 957-66.

Morrison DS, Batty GD, Kivimaki M, et al (2011). Risk factors for colonic and rectal cancer mortality: evidence from 40 years follow-up in the Whitehall I study. J Epidemiol Community Health, 65, 1053.58.

Nordenvall C, Nilsson PJ, Ye W, Andersson TM, Nyrén O (2013). Tobacco use and cancer survival: a cohort study of 40,230 Swedish male construction workers with incident cancer. Int J Cancer, 132, 155-61.

Oman National Cancer Registry Statistics (2012). Cancer Incidence in Oman.

Powell KP, Christianson CA, Hahn SE, et al (2013). Collection of family health history for assessment of chronic disease risk in primary care. $N C$ Med $J, 74,279-86$.

Rueda M, Robertson Y, Acott A, et al (2012). Association of tobacco and alcohol use with earlier development of colorectal pathology: should screening guidelines be modified to include these risk factors?. Am J Surg, 204, 963-8.

Spring B, Moller AC, Coons MJ (2012). Multiple health behaviours: overview and implications. J Public Health, 34, 3-10.

Seigel R, Naishadham D, Jemal A (2012). Cancer statistics 2013. CA Cancer J Clin, 63, 11-30.

Torre LA, Bray F, Siegel RL (2015). Global cancer statistics, 2012. CA Cancer J Clin, 65, 87-108.

Willett WC, Ludwig DS (2011). The 2010 dietary guidelines-the best recipe for health?. N Engl J Med, 365, 1563-5.

Wong CK, Lam CL, Poon JT, et al (2012). Direct medical costs of care for Chinese patients with colorectal neoplasia: a health care service provider perspective. J Eval Clin Pract, 18, 1203-10.

World Cancer research Fund (2017). Update report on colorectal cancer risk. Retrieved from http://www.wcrf.org/int/.

World Health Organization (2010). NCDs: Burden: mortality, morbidity and risk factors. Global status report on NCDs 2010. Retrieved from http://www.who.int/nmh/publications/ ncd_report_chapter1.pdf.

World Health Organization (2014). Cancer country profiles). Retrieved from http://www.who.int/cancer/country-profiles/ en/.

World Health Organization (2015). Obesity and overweight. fact sheet No. 311. Retrieved from http://www.who.int/ mediacentre/factsheets/fs311/en/.

World Health Organization (2016). Physical activity fact sheet. Retrieved from http://www.who.int/mediacentre/factsheets/ fs385/en/.

Yabroff KR, Borowski L, Lipscomb J (2013). Economic studies in colorectal cancer: challenges in measuring and comparing costs. J Natl Cancer Inst Monogr, 46, 62-78.

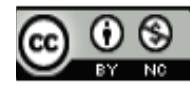

This work is licensed under a Creative Commons AttributionNon Commercial 4.0 International License. 